\title{
Nevirapine-induced Stevens-Johnson syndrome in children living with HIV in South Africa
}

\begin{tabular}{|c|c|}
\hline \multicolumn{2}{|c|}{$\begin{array}{l}\text { Authors: } \\
\text { Jacques D. du Toit }{ }^{1,2} \\
\text { Koot Kotze } \\
\text { Helene-Mari van der } \\
\text { Westhuizen }^{1,3} \text { (D) } \\
\text { Taryn L. Gaunt }{ }^{1} \text { (D) }\end{array}$} \\
\hline \multicolumn{2}{|c|}{$\begin{array}{l}\text { Affiliations: } \\
{ }^{1} \text { HIV Outpatient Department, } \\
\text { Zithulele Hospital, Mqanduli, } \\
\text { South Africa }\end{array}$} \\
\hline \multicolumn{2}{|c|}{$\begin{array}{l}{ }^{2} \text { MRC/Wits Rural Public } \\
\text { Health and Health Transitions } \\
\text { Research Unit, School of Public } \\
\text { Health, University of the } \\
\text { Witwatersrand, Johannesburg, } \\
\text { South Africa }\end{array}$} \\
\hline \multicolumn{2}{|c|}{$\begin{array}{l}{ }^{3} \text { Nuffield Department of } \\
\text { Primary Healthcare Sciences, } \\
\text { University of Oxford, Oxford, } \\
\text { United Kingdom }\end{array}$} \\
\hline \multicolumn{2}{|c|}{$\begin{array}{l}\text { Corresponding author: } \\
\text { Jacques D. du Toit, } \\
\text { jacques.dutoit1@wits.ac.za }\end{array}$} \\
\hline \multicolumn{2}{|c|}{$\begin{array}{l}\text { Dates: } \\
\text { Received: } 22 \text { Oct. } 2020 \\
\text { Accepted: } 09 \text { Dec. } 2020 \\
\text { Published: } 23 \text { Feb. } 2021\end{array}$} \\
\hline \multicolumn{2}{|c|}{$\begin{array}{l}\text { How to cite this article: } \\
\text { Du Toit JD, Kotze K, Van der } \\
\text { Westhuizen H-M, Gaunt TL. } \\
\text { Nevirapine-induced } \\
\text { Stevens-Johnson syndrome in } \\
\text { children living with HIV in } \\
\text { South Africa. S Afr J HIV Med. } \\
\text { 2021;22(1), a1182. https:// } \\
\text { doi.org/10.4102/sajhivmed. } \\
\text { v22i1.1182 }\end{array}$} \\
\hline \multicolumn{2}{|l|}{ Read online: } \\
\hline 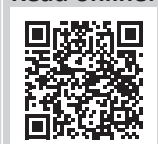 & $\begin{array}{l}\text { Scan this QR } \\
\text { code with your } \\
\text { smart phone or } \\
\text { mobile device } \\
\text { to read online. }\end{array}$ \\
\hline
\end{tabular}

Background: Although adverse drug reactions resulting from the use of nevirapine (NVP) are well described in adults (estimated frequency of $6 \%-10 \%$ ), it has previously been considered less common in children $(0.3 \%-1.4 \%)$. Stock-outs of antiretroviral agents occur frequently in South Africa and result in interruptions in therapy and drug substitutions.

Objectives: To report on a case series of paediatric patients who suffered cutaneous drug reactions to NVP at rates not previously described in children.

Method: We describe a retrospective observational case series of six children living with HIV who developed Stevens-Johnson Syndrome (SJS) following exposure to NVP because of a prolonged stock-out of efavirenz $200 \mathrm{mg}$ tablets in South Africa.

Results: Of the 392 paediatric patients receiving antiretroviral therapy at the institution, 172 were affected by the efavirenz stock-out. Of these, 85 children were changed to NVP of which six developed NVP-induced SJS (7.1\% incidence rate). The median time between initiating NVP and developing symptoms was 27 days (range 12-35 days). All patients responded well to NVP cessation and symptomatic treatment. One patient was referred for specialist care. Two patients were successfully rechallenged with efavirenz after developing SJS and three continued lopinavir/ritonavir.

Conclusions: This is the second largest case series of NVP-induced SJS in children to date and raises the possibility that the incidence of SJS in children may be higher than previously described. Further research is required to explore the risk factors associated with NVP-induced SJS in children. This case series highlights the negative impact of drug stock-outs on patient health outcomes.

Keywords: nevirapine; Stevens-Johnson syndrome; toxic epidermal necrolysis; paediatric; HIV; stock-outs.

\section{Introduction}

Stevens-Johnson Syndrome (SJS) and its severe form, toxic epidermal necrolysis (TEN), are mucocutaneous reactions associated with significant morbidity and mortality. ${ }^{1}$ Stevens-Johnson syndrome/toxic epidermal necrolysis may be caused by a wide range of medications and infections, and in many cases, it may be difficult to definitively establish the causative agent. ${ }^{2}$

Stevens-Johnson syndrome and TEN are thought to be delayed hypersensitivity reactions resulting from interactions between the drug and the adaptive immune system via specific human leukocyte antigen (HLA) subtypes and T-cell receptors. ${ }^{3}$ These drug metabolites likely result in immune mediated apoptosis of keratinocytes and eventual epidermal detachment. ${ }^{4}$ The time between exposure to a causative agent and onset of symptoms is estimated to be between 4 and 28 days. $^{2}$ It has also been hypothesised that human immunodeficiency virus (HIV) infection itself may increase the risk of developing SJS/TEN. ${ }^{1,5}$

The non-nucleoside reverse transcriptase inhibitor (NNRTI) nevirapine (NVP) is a wellestablished cause of SJS/TEN in adults but is thought to be uncommon in children. ${ }^{3}$ We accessed nine reports of SJS/TEN in children exposed to NVP describing 29 patients in total. ${ }^{6,7,8,9,10,11,12,13,14}$ Although NVP hypersensitivity has been associated with higher CD4 cell counts in adults ( $>250$ cells $/ \mu \mathrm{L}$ in females and $>400$ cells $/ \mu \mathrm{L}$ in males), the above case reports show SJS and TEN occurring at any stage of immune suppression in paediatric populations. ${ }^{8}$ It has been suggested

Copyright: (๑) 2021. The Authors. Licensee: AOSIS. This work is licensed under the Creative Commons Attribution License. 
that the paucity of cases reporting on the association between NVP in children and SJS/TEN may be a result of prescribing behaviour rather than an actual decreased risk compared with adults. ${ }^{2}$ However, there is widespread use of NVP in infants as part of prevention of mother-to-child transmission (PMTCT) programmes and we could only find reference to two cases of children below 1 year developing SJS following exposure to NVP. ${ }^{8}$ The reasons for this remain unclear, although greater immune tolerance in neonates may play a role.

It is estimated that $6 \%-10 \%$ of adults exposed to NVP will develop some form of drug-induced hypersensitivity, which may be grouped into one of five phenotypes: NVP-induced rash, hypersensitivity syndrome, SJS, toxic epidermal necrolysis, and drug-induced liver injury. ${ }^{15}$ The estimated risk for SJS/TEN in drug safety profile studies in adult and paediatric patients with HIV on NVP-containing regimens was previously thought to be approximately $0.3 \%{ }^{16}$ This contrasts with the estimated $1.4 \%$ incidence encountered by the largest case series of NVP associated SJS/TEN in pediatric patients to date. ${ }^{8}$

The National Consolidated Guidelines for PMTCT and the management of HIV in children, adolescents and adults, published by the Department of Health of South Africa in 2015 lists efavirenz (EFV) as the preferred NNRTI in children ( $>4$ weeks old) and adults, but allows for the use of NVP in first line regimens in neonates and in adolescents where EFV is contraindicated. It does not specify CD4 cell counts or percentages at which the use of NVP in antiretroviral (ARV) regimens of children is contraindicated. ${ }^{17}$ The updated 2019 guideline recommends switching children to Dolutegravirbased regimens in South Africa and does not provide recommendations on the use of NVP. ${ }^{18}$ A NVP-containing regimen is still recommended when initiating ART during the neonatal period and further information about potential risks and benefits for its use in children are important, as drug stock-outs lead to clinicians making individualised treatment decisions based on available ARVs.

Stock-outs of antiretroviral treatment, defined by the World Health Organization as the complete unavailability of a specific drug at a delivery or storage point for at least 1 day, are common in South Africa's antiretroviral therapy (ART) programme and may lead to worse health outcomes and virological failure. ${ }^{19,20}$ Stock-outs disrupt HIV care programmes and pose challenging treatment decisions when the preferred drug is not available. After an adverse event, it is also difficult to decide whether a drug in the same class can be re-introduced; although it has been shown that it is safe to restart EFV in patients who had SJS because of NVP. ${ }^{21}$ In this article we describe SJS that developed in children after switching to NVP during an EFV stockout.

\section{Methods}

\section{Background}

During February to May 2018 there was a prolonged stockout of $200 \mathrm{mg}$ EFV tablets at a rural hospital in the Eastern
Cape, South Africa. A strategy was developed by the Acting Clinical Manager and Head Pharmacist in conjunction with a paediatric infectious disease specialist to limit the effects on patient care. Children were switched to the best possible alternative treatment regimens, taking drug stock levels and individual case details into account. A viral load cut-off was used to split the large cohort of children into those who were fully or partially suppressed and those who had a higher level of viraemia. A viral load of 400 copies $/ \mathrm{mL}$ was used as this was the lowest level of viral suppression that the laboratory could accurately measure in the period preceding the stock-out. There were also limited supplies of EFV $50 \mathrm{mg}$ tablets and lopinavir/ritonavir $(\mathrm{LPV} / \mathrm{r})$, so it was not possible to transition the entire cohort to these alternatives. Children with a viral load deemed acceptable given the circumstances $(<400$ copies $/ \mathrm{mL}$ in the preceding 6 months) were switched to either NVP or dispensed the required EFV dose using $50 \mathrm{mg}$ tablets. As a result of the the concern of rapidly depleting the EFV $50 \mathrm{mg}$ tablet supply and further disrupting treatment in younger children, older children were preferentially changed to NVP. If children were not adequately virally suppressed ( $>400$ copies $/ \mathrm{mL}$ in the preceding 6 months), they were changed to second line therapy and thus received LPV/r. Children who were on 400 $\mathrm{mg}$ EFV were switched to $400 \mathrm{mg}$ immediate release (IR) NVP nocte and those on $300 \mathrm{mg}$ EFV were switched to IR NVP $200 \mathrm{mg}$ in the morning and $100 \mathrm{mg}$ in the evening based on local institutional practice.

\section{Study design}

This study is a retrospective observational case series describing the clinical course of a cohort of children living with HIV who developed an adverse drug reaction after substitution of their antiretroviral drugs. The researchers had no prior intention to evaluate the effects of NVP in this population preceding the substitution and the decision to write up the cases was made retrospectively. Clinical and drug prescription information was extracted from routinely collected HIV service programmatic data and paediatric ward admission notes. Contextual information regarding the HIV programme and treatment history was obtained through theiDART (intelligent Dispensing of ART) electronic record keeping system.

There are no universally accepted diagnostic criteria for SJS / TEN. A minimum of two of the following clinical features with the history of new exposure to NVP were used as inclusion criteria for this case series: prodrome of acute-onset febrile illness and malaise; painful rash that progresses rapidly; erythematous macules, targetoid lesions, vesicles, or bullae; positive Nikolsky sign; and mucosal involvement. ${ }^{22}$ Total Body Surface Area (TBSA) percentage involvement was documented using the Lund and Browder Chart to distinguish between SJS $(<10 \%)$, SJS / TEN overlap $(10 \%-30 \%)$, and TEN $(>30 \%)^{23}$.

\section{Ethical consideration}

Ethical approval was granted from the Human Research Committee at Walter Sisulu University's Faculty of Health 
Sciences Postgraduate Education, Training, Research and Ethics Unit (Ref: 022/2019). Permission for the study was attained from the relevant institutions and the Eastern Cape Health Research Committee (Ref: EC_201907_013). Written consent was obtained from the primary caregivers of children included in this case series.

\section{Results}

The EFV $200 \mathrm{mg}$ tablet stock-out affected 172 children. This represented $44 \%$ of the total paediatric population (age $<15$ years) collecting ARV treatment in the hospital catchment area at that time $(n=392)$. Eighty-five patients were switched from EFV to NVP, with the remaining patients either receiving $\mathrm{EFV}$ in $50 \mathrm{mg}$ tablets (34 patients), LPV/r (45 patients), sourcing EFV $200 \mathrm{mg}$ tablets elsewhere (3 patients), or were lost to follow-up (5 patients).

Six cases of SJS/TEN (incidence rate $=7.1 \%$, 95\% CI: $1.6 \%-12.5 \%$ ) were reported. Five of the six patient's caregivers consented to link clinical records with this case series, and this review will discuss details of those children. Based on these notes, no other new medication had been prescribed surrounding the introduction of NVP and SJS/TEN was the most likely clinical diagnosis. The mean age of the participants was 10.4 years (SD: 2.9) and the mean weight was $26.8 \mathrm{~kg}$ (SD: 4.9) (Table 1). Five of the children were receiving abacavir $(A B C) /$ lamivudine (3TC)/EFV before the drug switch. One child had confirmed prior exposure to NVP through the PMTCT programme. All children were reportedly healthy preceding their exposure to NVP, with no concurrent treatment initiation recorded.

The median time between initiating NVP and developing symptoms was 27 days (range 12-35 days). All patients responded well to NVP cessation, symptomatic treatment, and eye care if applicable. One patient was referred for tertiary care. Two patients were successfully rechallenged with EFV after developing SJS/TEN and the other three continued $\mathrm{LPV} / \mathrm{r}$.

\section{Discussion}

Prior to this case series, few cases of SJS/TEN in children after exposure to NVP have been described in the literature, with some experts believing that NVP associated SJS/TEN is uncommon in children living with HIV. $6,7,8,9,10,11,12,13,14$ Our case series showed an incidence rate of $7.1 \%$ of SJS/TEN after exposure to NVP because of a stock-out of EFV $200 \mathrm{mg}$ tablets. This was higher than previously estimated $(0.3 \%$ and $1.4 \%)$, however, given the small number of cases, the $95 \%$ confidence interval is wide $(1.6 \%-12.5 \%)$, and the true incidence in a larger population may be lower than what we found and closer to these estimates. Our result, and the true estimate, may however be higher than previously estimated and instead be congruent with the estimated incidence of NVP hypersensitivity in adults. ${ }^{8,16}$

We postulate that the reasons for the higher than expected incidence rate may be related to a genetic predisposition to developing NVP-induced SJS/TEN in this cohort of patients. Increasing bodies of literature are describing strong associations between HLA alleles and severe cutaneous adverse reactions with certain drugs. ${ }^{24}$ Although there are limited studies on SJS/TEN in sub-Saharan Africa, there is some evidence linking specific HLA subtypes (such as HLA-Cw*04) to NVP-induced SJS in populations from these regions. ${ }^{15,25}$ Adverse events relating to NVP have also been shown to strongly associate with single nucleotide polymorphisms in genes known to influence the rate of plasma clearance of NVP. ${ }^{25}$

TABLE 1: Case information of patients with Stevens-Johnson syndrome/toxic epidermal necrolysis.

\begin{tabular}{|c|c|c|c|c|c|c|}
\hline Characteristics & Case 1 & Case 2 & Case 3 & Case 4 & Case 5 & Case 6 \\
\hline Age (years) & 7 & 14 & 11 & 12 & 8 & $\S$ \\
\hline Sex & Female & Male & Male & Male & Male & $\S$ \\
\hline Weight (kg) & 19 & 29 & 30 & 31 & 25 & $\S$ \\
\hline Original ART initiation & $2017 / 01$ & $2006 / 09$ & $2009 / 05$ & $2009 / 04$ & $2017 / 02$ & $\S$ \\
\hline CD4 count at ART initiation & $565(2017 / 01)$ & Not available & Not available $\ddagger$ & $\begin{array}{l}1652(28 \%) \\
2009 / 04\end{array}$ & $362(2016 / 01)$ & $\S$ \\
\hline $\begin{array}{l}\text { Most recent CD4 count in } \\
\text { cells } / \mu \mathrm{L}(\% \text {, date) }\end{array}$ & $\begin{array}{c}654 \\
(33.3 \%, 2018 / 01)\end{array}$ & $\begin{array}{c}561 \\
(2016 / 08)\end{array}$ & $\begin{array}{c}1218 \\
(44.5 \%, 2015 / 09)\end{array}$ & Not available & Not available & $\S$ \\
\hline Previous ART regimen & $\mathrm{ABC} / 3 \mathrm{TC} / \mathrm{EFV}$ & $\mathrm{ABC} / 3 \mathrm{TC} / \mathrm{EFV}$ & $\begin{array}{l}\text { D4T/3TC/EFV then } \\
\text { ABC/3TC/EFV }\end{array}$ & $\begin{array}{l}\text { D4T/3TC/EFV then } \\
\text { ABC/3TC/EFV }\end{array}$ & $\begin{array}{l}\text { PMTCT NVP then } \\
\text { ABC/3TC/EFV }\end{array}$ & $\S$ \\
\hline Change during stock out & $\mathrm{ABC} / 3 \mathrm{TC} / \mathrm{NVP}$ & $\mathrm{ABC} / 3 \mathrm{TC} / \mathrm{NVP}$ & $\mathrm{ABC} / 3 \mathrm{TC} / \mathrm{NVP}$ & D4T/3TC/NVP & $\mathrm{ABC} / 3 \mathrm{TC} / \mathrm{NVP}$ & $\S$ \\
\hline NVP dose & $200 \mathrm{mg} \mathrm{am} / 100 \mathrm{mg} \mathrm{pm}$ & $400 \mathrm{mg}$ nocte & $400 \mathrm{mg}$ nocte & $400 \mathrm{mg}$ nocte & $400 \mathrm{mg}$ nocte & $\S$ \\
\hline $\begin{array}{l}\text { Days before onset of } \\
\text { symptoms }\end{array}$ & 27 & 12 & 35 & 21 & 28 & $\S$ \\
\hline Rash type and distribution & No rash & Generalised rash & Generalised rash & Generalised rash & Generalised rash & $\S$ \\
\hline Classification $\dagger$ & SJS & SIS & TEN & SJS & SIS & $\S$ \\
\hline $\begin{array}{l}\text { Mucous membrane } \\
\text { involvement }\end{array}$ & Lip ulceration & $\begin{array}{l}\text { Lip ulceration; } \\
\text { Conjunctival } \\
\text { hyperaemia }\end{array}$ & $\begin{array}{l}\text { Lip and oral ulceration; } \\
\text { Ulcerated glans }\end{array}$ & $\begin{array}{l}\text { Conjunctival } \\
\text { hyperaemia }\end{array}$ & Lip ulceration & $\S$ \\
\hline Blood investigations & Normal & ALT $1.5 \times$ Normal & ALT $1.5 \times$ Normal & Normal & Normal & $\S$ \\
\hline
\end{tabular}

ALT, alanine transferase; ART, antiretroviral therapy; D4T, stavudine; ABC, abacavir; 3TC, lamivudine; NVP, nevirapine; EFV, efavirenz; PMTCT, prevention of mother to child transmission; SJS,

Stevens-Johnson syndrome; TEN, toxic epidermal necrolysis.

$\dagger$, Total body surface area: SJS $(<10 \%)$; SJS/TEN overlap $(10 \%-30 \%)$; and TEN $(>30 \%)$.

$¥$, Results not available at point of data extraction.

$\S$, SJS recorded as adverse outcome on electronic database, but not linked with case notes as caregiver declined participation in case series. 
We were unable to perform an analysis to investigate the influence of CD4 cell count on the incidence of SJS in our dataset, and further research could help clarify whether this is a contributing factor in children, as it is a known risk factor for adverse reactions to NVP in adults. ${ }^{26}$

The NVP tablets used were an IR formulation as the $400 \mathrm{mg}$ extended release formulation was not available. Whilst some participants received this formulation as two divided doses, others received this as a single dose. Based on this and SJS being an immunological, dose independent reaction, ${ }^{27}$ we are uncertain of the contribution of this to a higher than expected incidence of SJS in this cohort.

The demographic characteristics of the patients in this case series are similar to those described in the literature. The time to onset of symptoms was similar to that seen in previously described cases of SJS/TEN (4-28 days), with a median of 27 days (range 12-35 days) amongst the patients treated in this series. The most severe case of TEN in our series had the longest interval between switching to NVP and presenting with symptoms (35 days). This could be because of delays in accessing healthcare in a rural setting, rather than an actual extended time before onset of symptoms.

This case series also demonstrates the difficulty of safely managing drug stock-outs, especially in rural healthcare settings. Given the difficulty of switching a large group of patients to a single alternative and the potential for triggering further stock-outs in other medications in a 'knock-on' effect, individualised substitutions had to be made in consultation with paediatric HIV experts. Unfortunately, and possibly because of a combination of the given contributing factors, the incidence of NVP associated SJS/TEN in our setting was far greater than previously reported in the literature. Knowledge of this case series may influence risk-benefit assessments in future similar scenarios and assist clinicians in selecting safer alternative regimens for children living with HIV. Although we as authors advise against the use of NVP in this type of patient, stock-outs are an unfortunate reality and NVP may be the only available alternative. If a clinician has exhausted all other options as outlined in their national guidelines (such as the use of Dolutegravir or $\mathrm{LPV} / \mathrm{r}$ ) and a drug holiday is not appropriate, we advise the following approach:

- The patient and their responsible guardian be counselled regarding the potential risks and early warning signs of SJS.

- Increase monitoring frequency (approximately a 2- and 4-week follow-up).

- Avoid addition of other new medication.

\section{Limitations}

Information for this case series was collected retrospectively and not all desired data were available. Furthermore, most of the patients were managed by different clinicians, resulting in differences in diagnostic criteria used and drug histories. The authors made every effort to ensure that the data collected was accurate despite these difficulties.

As a result of the mobility of patients using health services in the region of the study, it is also possible that there were more cases of SJS/TEN or other adverse reactions in the NVP-substitution cohort. These patients may have presented for healthcare elsewhere, although only one patient was lost to follow-up in the NVP-substitution cohort.

\section{Conclusions}

The risk of NVP-induced SJS/TEN in children living with HIV may be significantly higher than previously documented. Medication shortages have a negative impact on HIV care, and strategies to prevent stock-outs should be a key part of health system strengthening. National directives should be made available to assist healthcare workers in safely caring for patients when shortages occur.

\section{Acknowledgements}

We would like to thank Dr Jennifer Minnaar for her assistance in planning the initial stages of the research and her support in starting the data collection. We are grateful for Associate Professor Angela Dramowski for her valuable feedback on this article. We would like to thank the Zithulele ARV team and Catherine Young for their assistance in data collection.

\section{Competing interests}

The authors declare that they have no financial or personal relationships that may have inappropriately influenced them in writing this article.

\section{Authors' contributions}

J.D.d.T. completed data extraction, T.L.G. obtained informed consent from caregivers, J.D.d.T., T.L.G., K.K. and H.M.v.d.W . contributed equally to the conceptualisation and writing of this manuscript.

\section{Funding information}

This research received no specific grant from any funding agency in the public, commercial or not-for-profit sectors.

\section{Data availability}

The manuscript is a case series and thus there are no publically available datasets to refer to.

\section{Disclaimer}

The views and opinions expressed in this article are those of the authors and do not necessarily reflect the official policy or position of any affiliated agency of the authors. 


\section{References}

1. Levi N, Bastuji-Garin S, Mockenhaupt M, et al. Medications as risk factors of Stevens Johnson syndrome and toxic epidermal necrolysis in children: A pooled analysis. Pediatrics. 2009;123(2):e297-e304. https://doi.org/10.1542/peds.2008-1923

2. Dodiuk-Gad RP, Chung W-H, Valeyrie-Allanore L, Shear NH. Stevens-Johnson syndrome and toxic epidermal necrolysis: An update. Am J Clin Dermatol. 2015; 16(6):475-493. https://doi.org/10.1007/s40257-015-0158-0

3. Ferrandiz-Pulido C, Garcia-Patos V. A review of causes of Stevens-Johnson syndrome and toxic epidermal necrolysis in children. Arch Dis Child. 2013, 98(12):998-1003. https://doi.org/10.1136/archdischild-2013-303718

4. Roujeau J-C, Stern R. Severe adverse cutaneous reactions to drugs. N Engl J Med. 1994;331(1):1272-1285. https://doi.org/10.1056/NEJM199411103311906

5. Tebruegge $\mathrm{M}$, Ritz $\mathrm{N}$, Connell T, Curtis $\mathrm{N}$. Human immunodeficiency virus-infected boy with Stevens-Johnson syndrome caused by nevirapine. Pediatr Infect Dis J. 2008;27(11):130-132. https://doi.org/10.1097/INF.0b013e318185fb3a

6. Mason AR, Cortes GY, Pollack RB. Nevirapine-induced Stevens-Johnson syndrome in a pediatric patient. Pediatr Dermatol. 2008;25(1):128-129. https://doi. org/10.1111/j.1525-1470.2007.00605.x

7. Liechty CA, Solber P, Mwima G, Weidle PJ, Mermin J. Nevirapine-induced StevensJohnson syndrome in a mother and son. AIDS. 2005;19(9):989-994. https://doi. org/10.1097/01.aids.0000171419.29905.93

8. Dziuban EJ, Hughey AB, Stewart DA, et al. Stevens-Johnson syndrome and HIV in children in Swaziland. Pediatr Infect Dis J. 2013;32(12):1354-1358. https://doi. org/10.1097/INF.0b013e31829ec8e5

9. Oberdorfer $\mathrm{P}$, Washington $\mathrm{CH}$, Jittamala P. Human immunodeficiency virusinfected boy with Stevens-Johnson syndrome caused by nevirapine. Pediatr Infect Dis J. 2008;27(6):572-573. https://doi.org/10.1097/INF.0b013e31816d5fa2

10. Tchetnya X, Ngwasiri C, Munge T, Aminde L. Severe eye complications from toxic epidermal necrolysis following initiation of Nevirapine based HAART regimen in child with HIV infection: A case from Cameroon. BMC Pediatr. 2018;18(1):1-6. https://doi.org/10.1186/s12887-018-1088-9

11. Balasundaram S, Ranganathan $\mathrm{K}$, Umadevi $\mathrm{K}$, et al. Oral lesions associated with nevirapine-related Stevens Johnson syndrome: A report of four cases. J Ora Maxillofac Pathol. 2011;15(1):39-45. https://doi.org/10.4103/0973-029X.80024

12. Norris JM, Stuttaford LH, Sichinga $P$, et al. A severe case of antiretroviral therapyinduced toxic epidermal necrolysis in a child. Arch Dis Child. 2012;97(Supp 1):A41-A42. https://doi.org/10.1136/archdischild-2012-301885.101

13. Obebi Cliff-Eribo K, Sammons H, Star K, et al. Adverse drug reactions in Nigerian children: A retrospective review of reports submitted to the Nigerian Pharmacovigilance Centre from 2005 to 2012. Paediatr Int Child Health 2016;36(4):300-304. https://doi.org/10.1179/2046905515Y.0000000059

14. Saka B, Akakpo AS, Bassowa A, et al. Non-nucleoside reverse transcriptase inhibitors (NNRTIs)-induced Stevens-Johnson syndrome and gynecomastia in an HIV-infected child: A case report. Ann Dermatol Venereol. 2018;145(12):773-776.
15. Carr DF, Chaponda M, Jorgensen AL, et al. Association of human leukocyte antigen alleles and nevirapine hypersensitivity in a Malawian HIV-infected population. Clin Infect Dis. 2013;56(9):1330-1339. https://doi.org/10.1093/cid/cit021

16. Pollard RB, Robinson P, Dransfield K. Safety profile of nevirapine, a nonnucleoside reverse transcriptase inhibitor for the treatment of human immunodeficiency
virus infection. Clin Ther. 1998;20(6):1071-1092. https://doi.org/10.1016/S01492918(98)80105-7

17. South African National Department of Health. National consolidated guidelines for the prevention of mother-to-child transmission of HIV (PMTCT) and the managment of HIV in children, adolescents and adults [homepage on the Internet]. 2015 [cited 2020 Apr 20]. Available from: https://sahivsoc.org/Files/ ART\%20Guidelines\%2015052015.pdf.

18. South African National Department of Health. National consolidated guidelines for the prevention of mother-to-child transmission of HIV (PMTCT) and the managment of HIV in children, adolescents and adults [homepage on the Internet]. 2015 [cited $2020 \mathrm{Apr} 20$ ]. Available from: https://sahivsoc.org/Files/ 2019\%20Abridged\%20ART\%20Guidelines\%2010\%200ctober\%202019.pdf

19. Hwang B, Shroufi A, Gils T, et al. Stock-outs of antiretroviral and tuberculosis medicines in South Africa: A national cross-sectional survey. PLoS One. 2019;14(3):1-13. https://doi.org/10.1371/journal.pone.0212405

20. Kranzer K, Ford N. Unstructured treatment interruption of antiretroviral therapy in clinical practice: A systematic review. Trop Med Int Health. 2011;16(10): 1297-1313. https://doi.org/10.1111/j.1365-3156.2011.02828.x

21. Manzini TC, Gosnell BI, John MA, Moosa MYS. Efavirenz challenge in patients with nevirapine induced Stevens-Johnson Syndrome. S Afr J Infect Dis. 2016;31(4): 119-121. https://doi.org/10.1080/23120053.2016.1156874

22. High WA, Roujeau J-C. Stevens-Johnson syndrome and toxic epidermal necrolysis: Pathogenesis, clinical manifestations, and diagnosis. Up-to-date [homepage on
the Internet]. Waltham, MA: UpToDate; 2018 [cited $2020 \mathrm{Apr} 20$ ]. Available from: the Internet]. Waltham, MA:
https://www.uptodate.com

23. French LE. Toxic epidermal necrolysis and Stevens Johnson Syndrome: Our current understanding. Allergol Int. 2006;55(1):9-16. https://doi.org/10.2332/ allergolint.55.9

24. Cheng C-Y, Su S-C, Chen C-H, Chen W-L, Deng S-T, Chung W-H. HLA associations and clinical implications in T-cell mediated drug hypersensitivity reactions: An updated review. J Immunol Res. 2014;2014:565320. https://doi.org/10.1155/ 2014/565320

25. Yuan J, Guo S, Hall D, et al. Toxicogenomics of nevirapine-associated cutaneous and hepatic adverse events among populations of African, Asian, and European descent. AIDS. 2011;25(10):1271-1280. https://doi.org/10.1097/QAD.0b013e 32834779df

26. Kesselring AM, Wit FW, Sabin CA, et al. Risk factors for treatment-limiting toxicities in patients starting nevirapine-containing antiretroviral therapy. AIDS. 2009; 23(13):1689-1699. https://doi.org/10.1097/QAD.0b013e32832d3b54

27. Mockenhaupt $M$, Viboud C, Dunant $A$, et al. Stevens-Johnson syndrome and toxic epidermal necrolysis: Assessment of medication risks with emphasis on recently marketed drugs. The EuroSCAR-study. J Invest Dermatol. 2008;128(1):35-44. https://doi.org/10.1038/sj.jid.5701033 